\title{
Cross check of the new economic and mass balance features of the fuel cycle scenario code TR EVOL
}

\author{
Iván Merino-Rodríguez, Manuel García-Martínez, Francisco Álvarez-Velarde*, and Daniel López \\ CIEMAT - Centro de Investigaciones Energéticas, Medioambientales y Tecnológicas, Av. Complutense 40, Ed. 17, 28040 \\ Madrid, Spain
}

Received: 10 February 2016 / Received in final form: 21 June 2016 / Accepted: 4 July 2016

\begin{abstract}
Versatile computational tools with up to date capabilities are needed to assess current nuclear fuel cycles or the transition from the current status of the fuel cycle to the more advanced and sustainable ones. This work is intended to cross check the new capabilities of the fuel cyclescenario code TR_EVOL. This process has been divided in two stages. The first stage is dedicated to check the improvements in the nuclear fuel mass balance estimation using the available data for the Spanish nuclear fuel cycle. The second stage has been focused in verifying the validity of the TR_EVOL economic module, comparing results to data published by the ARCAS EU project. A specific analysis was required to evaluate the back-end cost. Data published by the waste management responsible institutions was used for the validation of the methodology. Results were highly satisfactory for both stages. In particular, the economic assessment provides a difference smaller than $3 \%$ regarding results published by the ARCAS project (NRG estimations). Furthermore, concerning the back-end cost, results are highly acceptable $(7 \%$ difference for a final disposal in a once-through scenario and around $11 \%$ for a final disposal in a reprocessing strategy) given the significant uncertainties involved in design concepts and related unit costs.
\end{abstract}

\section{Introduction}

The study of the nuclear fuel cycle requires versatile computational tools or "codes" to provide answers to the multicriteria problem of assessing current nuclear fuel cycles or the capabilities of different strategies and scenarios with potential development in a country, region or at the world level. Moreover, the introduction of new technologies for reactors and industrial processes makes the existing codes to require new capabilities to assess the transition from the current status of the fuel cycle to the more advanced and sustainable ones [1,2].

In particular, the analysis of these dynamic fuel cycle scenarios usually includes different short, medium and longterm options for the introduction of various types of nuclear reactors. Also the usage of associated nuclear material and generation and management of nuclear waste is usually taken into account in these analyses, giving as well due consideration to the isotopic composition of the material in any stage of the fuel cycle (essentially uranium, plutonium, minor actinides and fission products). Besides, economic efficiency is one of the three pillars of the sustainable development along with the Environmental and Social dimensions [3], while competitiveness is a relevant indicator

\footnotetext{
* e-mail: francisco.alvarez@ciemat.es
}

insofar market prices reflect the full costs for society of a given product or activity. One of the indicators usually used in this sense is the LCOE, which is defined as the long-term breakeven price that investors should receive to cover all their costs, including an acceptable return on investment as expressed by the discount rate [4]. This cost is usually expressed as cost divided by a unit of generated energy, typically in cents $/ \mathrm{kWh}, \$(€) / \mathrm{MWh}$, etc.

This work is intended to cross check the new capabilities of the fuel cycle scenario code TR_EVOL [5] developed at CIEMAT by means of comparing its results with those published in bibliography in two different points of view: mass balance and economic estimations. Although the previous version of TR_EVOL has already been validated by means of benchmarking in the field of the OECD/NEA [1], the continuous updates and upgrades implemented to improve the fuel cycle model and the new economic module development make necessary a new verification. This process has been divided in two stages as described in Section 3. The TR EVOL code will be described to some detail in Section 2.

\section{TR_EVOL code}

The transition evolution code TR EVOL has been developed at CIEMAT with the aim of achieving the requirements of the research in the field of transition/ 
dynamic fuel cycle scenarios, by being able to simulate diverse fuel cycle scenarios and provide useful indicators and conclusions.

The previous version of the code [5], although including many capabilities, was not accurate enough for very complex simulations concerning the back-end (HLW as SF assemblies or UC-V and its disposal in interim storage or final disposal) and lacked the possibility of performing economic analyses. A special effort has been put to solve this issue. This section is aimed to describe the main capabilities of the code in terms of fuel cycle mass balance and of economic aspects.

\subsection{Fuel cycle mass balance}

The TR EVOL module devoted to fuel cycle mass balance simulates diverse nuclear power plants (PWR, SFR, ADS, etc.), having possibly different types of fuels $\left(\mathrm{UO}_{2}, \mathrm{MOX}\right.$, etc.), and the associated fuel cycle facilities (enrichment, fuel fabrication, processing, interim storage, waste storage, geological disposal). The module is intended to simulate the time dependent behavior of each reactor fleet as a single averaged macro-reactor, although it can also simulate individually each reactor of the fleet if required (demanding however larger computer resources). Due to this purpose and assuming that the nuclear fleet is large enough (usually tens of reactors), every magnitude is provided per year. Hence, large fluctuations of operational parameters on individual cycle facilities are averaged over the year.

The evolution of fuel isotopic composition of nuclear materials during the lifetime of the nuclear fleet is performed in TR_EVOL by means of ORIGEN 2.2 (Isotope Generation and Depletion Code) [6] specifically in the decay and irradiation processes. The physical model developed for the irradiation process is a group of three solution methods, the center of which is the matrix exponential method for solving differential equations [7].

In case of irradiation, ORIGEN 2.2 could use its own reference cross section libraries or others specifically calculated with EVOLCODE $2.0[8]$ averaging the cross sections dependence on geometry and irradiation time to obtain a representative (or more than one) library.

Each fuel cycle storage facility is represented by one or several different buffers. For instance, a nuclear fleet might consist of a series of PWR with $N$ different ${ }^{235} \mathrm{U}$ enrichments fuels. Hence, data concerning fresh fuels with different enrichments can be stored in $N$ different buffers containing the isotopic vector and the total amount of material present in that storage. Storage facilities taken into account in a general fuel cycle (other could be included when necessary for particular cycles) are fresh fuel for nuclear reactors, spent fuel in cooling storage, separated material from reprocessing and nuclear waste. Connections between buffers represent mass flows. They can link one buffer to another, but can also join more than two buffers or divide different buffers.

The parameters of the cycle facilities and the timedependent interconnections are described in TR_EVOL using a series of basic operational instructions or rules. Each rule specifies a particular action that is applicable to a particular buffer (decay of stored material, for instance) or to a particular interconnection (fuel irradiation, fuel fabrication, reprocessing, etc.). The period of time for which that particular action is active is also specified (for instance, advanced reprocessing may be only applicable from a certain year on).

As part of the continuous updates and upgrades implemented to improve the fuel cycle model, a series of improvements has been implemented in the code:

- Variable burn-up: The average annual burn-up can vary for different years of reactor operation.

- First and last cores treatment: The new fresh core mass at the beginning of cycle and the irradiated cores mass at the end of reactor operation are now taken into account.

- Management of the fission products and activation products: Fission products and activation products can now be treated together with actinides.

- Reprogramming of the code: Improvements in rules management, input files and other minor features allow improving robustness, debugability and efficient connection with the economic module.

\subsection{Economic module}

The economic module treats the information located in the main cost input file (other input files are needed in case that the disposal cost estimation is required) and applies the models and unit costs to the mass balance output previously obtained.

The cost simulation is based on the definitions and subdivisions of the costs presented here, which are mainly based in the economic models given by The Economic Modeling Working Group of the Generation IV International Forum [9]. This model divides the LCOE in four main components:

- Investment cost: This cost represents those costs related to the construction of the new reactor plant. It includes the overnight cost (specific cost for each reactor) and financial costs (interest during construction and interest for the loan).

- Fuel cost: It represents the front-end cost. However, the reprocessing cost, usually included into the back-end cost, is implicitly included here for fuels that require this process. Several fuel types are allowed in the economic module: $\mathrm{UO}_{2}, \mathrm{MOX}$ for PWR and SFR, and ADS. It also includes the cost of the new reactor cores (first charge). - O\&M cost: This cost represents an annual cost for the plant, as function of the installed capacity. Thus, the value used is a cost per GWe.

- Decommissioning \& Dismantling and Disposal cost: This item represents two different costs in TR_EVOL model. On the first hand, it includes Decommissioning \& Dismantling as a specific percentage of the overnight cost. On the other hand, it includes the disposal cost that considers the interim and the final disposal both separately calculated.

The estimation of the LCOE per reactor type is calculated adding its four cost items and then divided into the total energy generated by this reactor or fleet along the cycle. The estimation of the global LCOE for the total cycle is made by adding each $\mathrm{LCOE}$ per reactor type weighted by its contribution to the power demand. 
Table 1. General parameters for each reactor.

\begin{tabular}{llllll}
\hline Unit & Unit power $(\mathrm{GWe})$ & Load factor & Reactor type & Comm. date & Dec. date \\
\hline José Cabrera & 0.160 & 0.70 & PWR & 1969 & 2006 \\
S.M. Garoña & 0.466 & 0.78 & BWR & 1970 & 2013 \\
Almaraz I & 0.977 & 0.85 & PWR & 1981 & 2021 \\
Ascó I & 1.032 & 0.83 & PWR & 1983 & 2023 \\
Almaraz II & 0.980 & 0.87 & PWR & 1983 & 2023 \\
Cofrentes & 1.092 & 0.86 & BWR & 1984 & 2024 \\
Ascó II & 1.027 & 0.86 & PWR & 1985 & 2025 \\
Vandellós II & 1.087 & 0.81 & PWR & 1987 & 2027 \\
Trillo & 1.066 & 0.86 & PWR & 1988 & 2028 \\
\hline
\end{tabular}

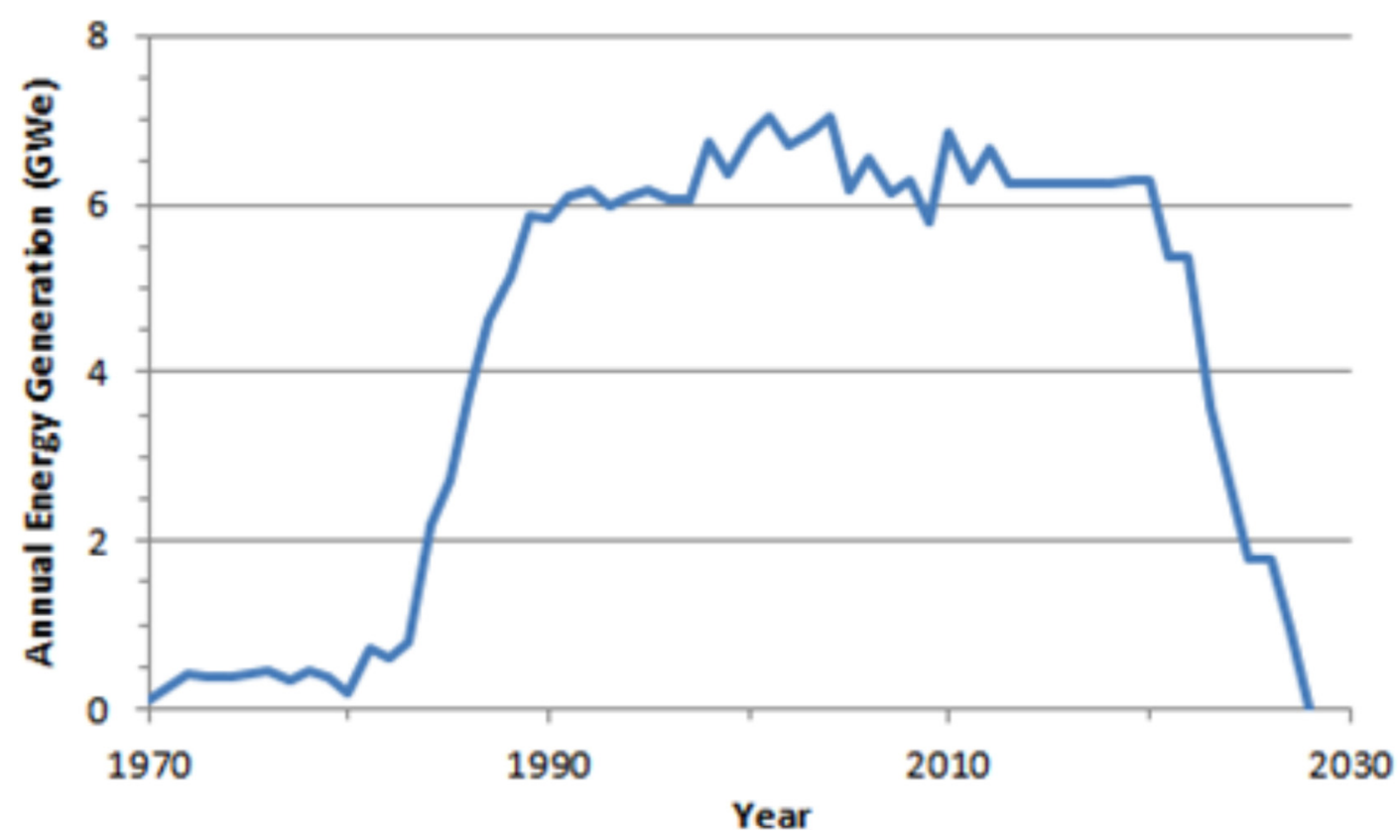

Fig. 1. Annual energy production of the Spanish nuclear fleet.

\section{Cross check of TR_EVOL capabilities}

\subsection{Fuel cycle mass balance: Spanish nuclear fuel cycle}

\subsubsection{Scenario details}

The analysis of the Spanish nuclear fuel cycle has been performed to validate the prediction power of the TR_EVOL module in one of the most relevant parameters of a fuel cycle: the inventory of irradiated fuel along the cycle. This fuel cycle has been chosen due to its simple scheme and its current open cycle strategy.

The Spanish fuel cycle scenario includes $2 \mathrm{BWR}$ and $7 \mathrm{PWR}$ and its period of electric generation starts in year 1969 and it is assumed to finish at year 2028. The characteristics of the reactors used in the simulation are shown in Table 1.

The electric generation evolution (per year) can be seen in Figure 1. Until year 2012 the energy production data was obtained from the IAEA database PRIS [10]. This data has been projected to the end of cycle. According to this estimation, the total electric energy produced is around 2178 TWhe.

The experimental data has been taken from ENRESA, the Spanish public company responsible of the nuclear waste management [11], specifically according to the SF in the reactor pools or interim storages at year 2005 .

An average burn-up of $40 \mathrm{GWd} / \mathrm{tU}$ has been assumed for all reactors excluding Cofrentes. For this nuclear power plant a more detailed irradiation history is available in bibliography [12]. This variable irradiation history, shown in Figure 2, has been used in this simulation.

\subsubsection{Scenario results}

As first parameter chosen to validate the code, ENRESA provides the mass to be stored at the end of cycle. The total mass produced by the cycle estimated by ENRESA is $6674 \mathrm{t}$, while the result provided by the simulation is $\sim 6820$ t. This difference represents a relative deviation of 


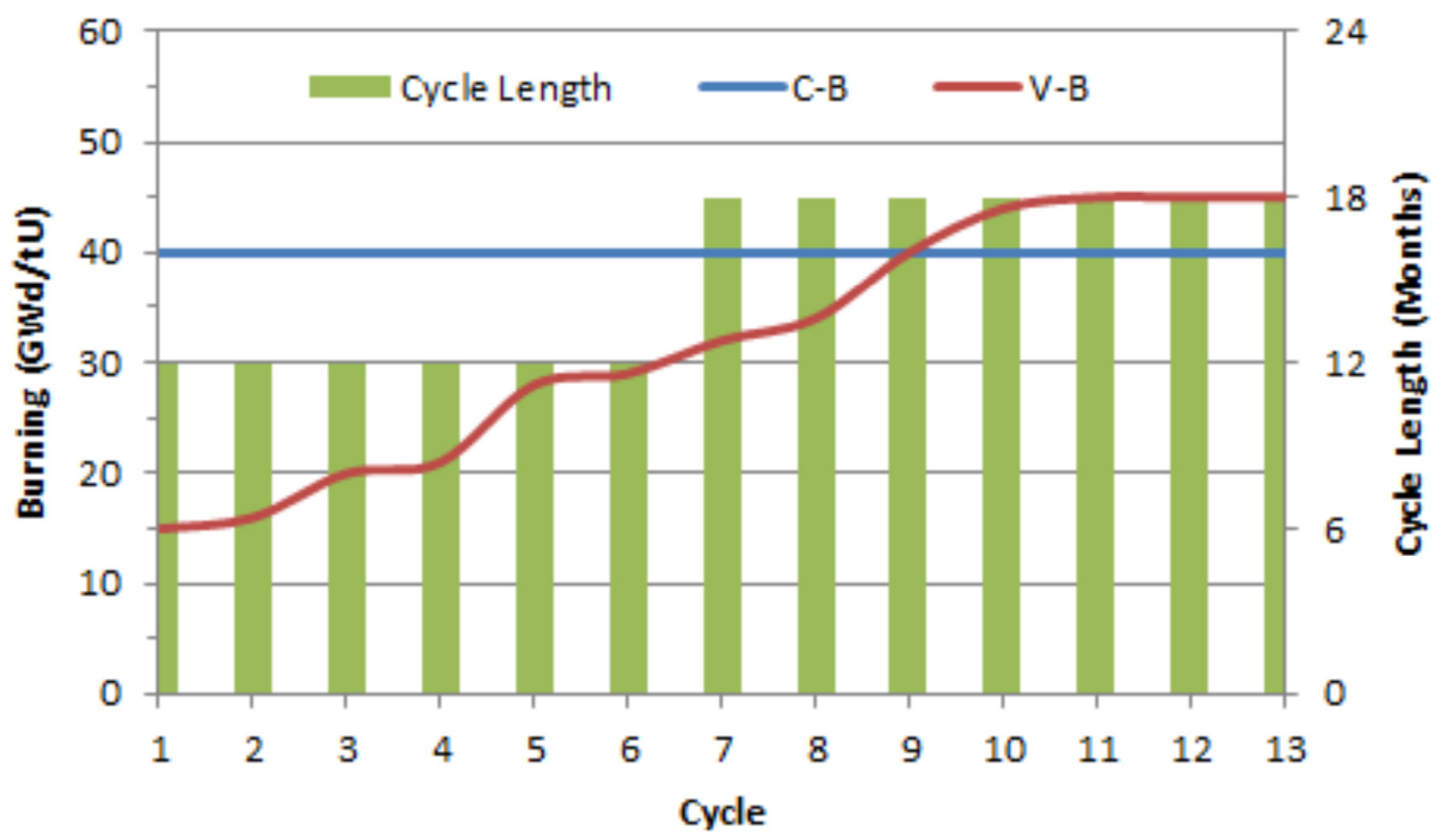

Fig. 2. Variable burn-up (V-B) used to simulate Cofrentes nuclear power plant, instead of constant burn-up (C-B).

Table 2. SF mass accumulated until year 2005 per reactor unit.

\begin{tabular}{lccc}
\hline Reactor pool & Simulation & ENRESA & $\begin{array}{l}\text { Relative } \\
\text { difference }(\%)\end{array}$ \\
\hline José Cabrera & 107 & 100 & -7.0 \\
S.M. Garoña & 270 & 311 & 13.2 \\
Almaraz I & 451 & 465 & 3.0 \\
Ascó I & 448 & 417 & -7.4 \\
Almaraz II & 438 & 432 & -1.4 \\
Cofrentes & 553 & 551 & 0.4 \\
Ascó II & 428 & 408 & -4.9 \\
Vandellós II & 380 & 360 & -5.6 \\
Trillo & 384 & 344 & -11.6 \\
Total & 3459 & 3388 & 2.1 \\
\hline
\end{tabular}

around $2 \%$ between both TR EVOL and ENRESA values, meaning that the model represents correctly the Spanish nuclear fleet. It has to be mentioned that certain compensation of underestimated and overestimated values takes place.

The SF stored in the reactor pools can be taken into account for a second comparison. Table 2 shows the SF in the reactor pools at year 2005 (for José Cabrera this year is 2006, its real decommissioning date) obtained by TR_EVOL simulation and the referenced value by each reactor provided by ENRESA.

Table 2 shows that the total SF mass predicted until year 2005 gives a value very closed to the result published in bibliography. However, certain compensations between PWR and BWR masses take place but deviations are usually smaller than $8 \%$. As it can be noted in the case of S. M. Garoña unit, BWR type, a significant deviation can be found between the simulation and published data. However, for the other BWR reactor, Cofrentes, applying a variable burn-up, negligible difference is found. In fact, if the constant burn-up of $40 \mathrm{GWd} / \mathrm{tU}$ was also used for this reactor, a relative difference of $21 \%$ can be found at year 2005 , showing the importance of having both sufficiently detailed data and a powerful simulation code (able to take into account variable burn-up over the lifetime of the reactor).

\subsection{Validation of the economic module: ARCAS \\ 3.2.1 Introduction}

The EU-funded project 'ADS and fast reactor comparison study in support of Strategic Research Agenda of SNETP' (ARCAS) [13] embarked on the mission of helping policymakers and governments to decide on the best options to streamline their nuclear facilities for more efficient energy production considering the maturity of the technology and how this could be incorporated into economic analyses.

Assessments included fuel cycle cost and transmutation with maximal minor actinide content involved in core loading, in addition to checking a number of safety parameters. The project successfully analyzed existing studies, outlining a legal framework of partitioning and transmutation operations.

The ARCAS economic document [14] (taken as reference for this evaluation) analyses economically different strategies for a nuclear fuel cycle scenario in order to give zero net production of MA for the whole reactor fleet. Applying two different economic models and hypotheses (by CNRS and NRG) for the ADS system (as EFIT configuration [15]) and two different types of FR (homogeneous and heterogeneous configurations), ARCAS provided the LCOE per reactor type and not for the whole cycle. Hence, the comparison will be made here for the FR and ADS technology type cost only. 
Table 3. FR and ADS estimation costs using TR_EVOL and NRG models.

\begin{tabular}{lll}
\hline Cost component & FR & ADS \\
& Relative error & Relative error \\
\hline Capital & $-0.5 \%$ & $-0.7 \%$ \\
O\&M & $1.1 \%$ & $0.6 \%$ \\
Fuel & $2.6 \%$ & $1.4 \%$ \\
LCOE & $0.3 \%$ & $-0.3 \%$ \\
\hline
\end{tabular}

In this work, two fuel cycle options (one scenario with ADS and other with FR homogeneous configuration) taken from this document have been chosen for their economic study. The economic model and hypotheses provided by NRG will be used here, since the methodologies used by NRG are closer to those implemented in TR EVOL.

The comparison has been carried out using the characteristics and parameters for FR and ADS proposed by ARCAS. Only costs related to the investment, fuel and O\&M have been evaluated here. On the contrary, the Decommissioning \& Dismantling and Disposal costs have not been considered for these simulations, because a more detailed analysis of these costs is needed to validate the code capability. This will be shown later.

\subsubsection{Scenario details}

The scenarios used in this study are:

- FR simulation: The scenario chosen for the assessment of the FR cost has been the homogeneous configuration with $70 \%$ of the energy provided by FR and $30 \%$ by PWR with $100 \% \mathrm{UO}_{2}$ fuel. In this scenario, the FR burn both the MA contained in their used fuels and the MA of the PWR stratum.

- ADS simulation: For the ADS, the model considers $97.4 \%$ of the energy production by PWR with $100 \% \mathrm{UO}_{2}$ fuel and the other $2.6 \%$ is provided by ADS. The ADS is designed to be dedicated to MA burning. As a consequence, it has a large MA burning capacity (estimation about $112.5 \mathrm{~kg} / \mathrm{TWhe}$ ). Although the share of electricity produced in ADS is small, the amount of ADS systems in the park is still quite significant, due to the small power per unit, of $400 \mathrm{MWth}$.

\subsubsection{Scenario results}

The results for the FR type, summarized in Table 3, include the estimations for all the items that explain the LCOE (excluding the DDD cost). It can be seen that outcomes from TR EVOL code are rather similar to those obtained by the NRG model simulation, with differences lower than $3 \%$. Analogous results are obtained with the ADS-reactor type simulation, also shown in Table 3 .

The comparison between the results obtained by TR_EVOL and ARCAS project (by means the NRG model) shows that the economic model works correctly for the three components of the LCOE analyzed: investment costs, fuel cost and O\&M cost. The Decommissioning \& Dismantling and Disposal cost will be analyzed in the next section.
Table 4. ID cost summary in M€.

\begin{tabular}{llll}
\hline Item & Swedish ID & Spanish ID & Average \\
\hline Fixed cost & 345 & 503 & 424 \\
$\begin{array}{l}\text { Investment cost } \\
\begin{array}{l}\text { Decomm. cost } \\
\text { Total }\end{array}\end{array}$ & 65 & 65 & 65 \\
$\begin{array}{l}\text { Variable cost } \\
\text { O\&M unit cost }\end{array}$ & 0.184 & 0.126 & 0.155 \\
$\begin{array}{l}\mathrm{M} € / \mathrm{t}) \\
\begin{array}{l}\text { O\&M unit cost } \\
(\mathrm{M} / \text { canister PWR) }\end{array}\end{array}$ & 0.342 & 0.234 & 0.290 \\
$\begin{array}{l}\text { O\&M unit cost } \\
(\mathrm{M} € / \text { canister BWR) }\end{array}$ & 0.397 & 0.272 & 0.335 \\
\hline
\end{tabular}

\subsection{Validation of the economic module: the back-end cost}

3.3.1 Decommissioning and dismantling cost

There is consensus in bibliography [16] about the cost of decommissioning and dismantling, expressed as a percentage depending on the overnight cost of the power plant. The percentages used for the TR_EVOL model, for a generic simulation, will be, as a best estimate obtained from an average of the published data, of a $15 \%$ of the overnight cost. No cross check has been hence made for this cost.

\subsubsection{Interim storage cost}

The model implemented in TR_EVOL for the interim storage cost is divided into two main costs: a fixed cost, which (a priori) does not depend on the mass to store, and a variable cost, depending on the mass to store. The FC of the interim storage facility is divided into Construction Cost and Dismantling Cost. The variable cost is formed by a number of canisters times the storage unit cost.

Published data about the Swedish interim storage $[17-19]$ and the Spanish interim storage $[11,20]$ have been used to fill these cost items, although both concepts of interim storage are very different: The Swedish concept is a wet storage and the Spanish one is a dry storage.

The results of this literature search have allowed us to obtain the main fixed and variable costs to use in the TR_EVOL model. These values are shown in Table 4. However, due to the lack of complete information about real concepts of interim storages, no cross check of the results of the model could be done. These values are then proposed to be used for a general concept of interim storage in the case that no referenced values are available.

\subsubsection{Final disposal cost}

The following analysis gives the outcomes for the FD cost and provides the unit costs necessary to estimate any generic FD cost through TR_EVOL economic module. Although a representative fixed cost for a general FD concept is difficult to obtain due to the lack of information, these values might serve as a first estimation. To do this analysis, the information for some countries presented in 
bibliography (for FD in open cycle $[11,19,21,22]$ and in scenarios with partial reprocessing $[23,24]$ ) has been followed. This information, about the SF mass generated by cycle and its estimated FD cost, is reinforced by the companies engaged in the development and construction of these facilities.

TR_EVOL approximation for FD costs is also explained by a fixed cost plus a variable cost. The fixed cost represents the sum of the overnight cost for the FD, the overnight cost for the EP, and the decommissioning cost of both. Besides, the variable cost is explained by the cost of storing and managing a certain SF mass, as follows:

$$
\text { Variable cost }=\mathrm{VC}(\mathrm{FD})+\mathrm{VC}(\mathrm{EP})+\mathrm{GC}(\mathrm{FD}),
$$

where

- VC (FD): O\&M cost of the FD, which includes the storing and conditioning of the canister to be stored.

- VC (EP): O\&M cost of the EP, including the canisters fabrication cost and the encapsulation process.

- GC (FD): Gallery length cost for the FD, expressed as a fixed unit cost per km of gallery.

The main challenge of this model is to find a representative value for the gallery cost. This value has to involve the tunneling cost and others related to canisters conditioning.

The estimation of the gallery length cost depends obviously on the mass to store, which can be worked out considering the number of canisters to store and their dimensions taken from the references. At first, the canister (or packages) number depends on the fuel type and the number of the SF assemblies that can be deposited. Considering the references for the Spanish, Swedish and Finnish FD, and assuming that these estimations can be applied for all FD in an Open Cycle strategy, the gallery length cost for FD, as a cost per km of gallery can be obtained solving the following expression for the parameter GC. For this process, the fixed costs and the other unit costs taken or calculated from the referenced data are used as follows:

$$
\begin{aligned}
\mathrm{FD} \operatorname{cost}= & \mathrm{FC}+\mathrm{VC} \\
= & \mathrm{FC}+\mathrm{NOC} \times(\mathrm{VC}(\mathrm{EP})+\mathrm{VC}(\mathrm{FD})) \\
& +\mathrm{GC} \times \mathrm{GL} .
\end{aligned}
$$

Applying this model to the Swedish, Finnish and Spanish FD and using their referenced costs, the GC unit cost obtained as an averaged value is around $19.7 \mathrm{M} € / \mathrm{km}$. Other generic values are presented in Table 5.

Table 6 shows a comparison of the referenced FD costs used for the estimation and the results obtained by TR_EVOL model. The relative errors between both sets of results are quite satisfactory, meaning that the model for a generic FD developed here can describe correctly the cost of the FD.

To explore the model representativeness, a different case has also been studied. The Canadian FD design, which has the biggest capacity of the world with almost 200,000 $\mathrm{t}$ of HM, is a good reference to contrast the unit costs estimated above. The result of the model also agrees reasonably well with the reference, with an underestimation of only $2.4 \%$. This result is fairly accurate despite the
Table 5. Summarized generic costs and parameters for FD model.

\begin{tabular}{ll}
\hline Item & Cost \\
\hline Fixed cost (including EP and decomm.) & $2130 \mathrm{M} €$ \\
Gallery length cost per km & $19.7 \mathrm{M} €$ \\
Encapsulation cost per canister & $0.203 \mathrm{M} €$ \\
Management/condition. cost & $0.042 \mathrm{M} €$ \\
(HM and HLW) & $465 \mathrm{~kg}$ \\
Mass per assembly & $56 \mathrm{~kg}$ \\
HLW mass per UC-V & $6.6 \mathrm{~m}$ \\
Canister length + separation & $1.8 \mathrm{~m}$ \\
UC-V length + separation & \\
\hline
\end{tabular}

dimension of the canister was unknown, so a canister length of $4.6 \mathrm{~m}$ plus a separation between canisters of $2 \mathrm{~m}$ has been used in the GL estimation (as for PWR).

Considering that the cost comparison above performed for FD in open cycles validates this model (provided that the correct parameters are used), the main question now is if this model can be also applied for FD in fuel cycles with reprocessing strategies. For that, two fuel cycle scenarios with partial reprocessing strategies (Switzerland and France) are assessed. Table 7 shows the mass requirements for storage and the cost estimation given by bibliography and the estimation made by TR EVOL model.

For Switzerland, which is planning to reprocess around one third of its $3400 \mathrm{t}$ of SF generated, the projected cost is $3020 \mathrm{M} €$. Applying the model to the $2200 \mathrm{t}$ of $\mathrm{UO}_{2} \mathrm{SF}$ stored as in the open cycle case and the $52 \mathrm{t}$ of HLW generated from the $1200 \mathrm{t}$ of $\mathrm{UO}_{2}$ reprocessed stored in $\mathrm{UC}-\mathrm{V}$, the result is close to the referenced value with a $7.9 \%$ difference.

On the other hand, for French FD case, the full reprocessing assumption taken from the International Panel of Fissile Materials [23] was assessed. This reference argues that at the end of the scenario $17,600 \mathrm{t}$ of $\mathrm{UO}_{2}$ and $4800 \mathrm{t}$ of MOX are placed along with $1320 \mathrm{t}$ of HLW from the reprocessing of $36,100 \mathrm{t}$ of $\mathrm{UO}_{2}$ (instead of storing $58,300 \mathrm{t}$ of $\mathrm{UO}_{2}$ for a hypothetical open cycle strategy). The result shows that the value calculated by TR EVOL model underestimates the reference value by an $1 \overline{1} \%$.

Despite the significant relative errors in both reprocessing cases, the values from the estimation are rather close to those presented by the references. However it is clear that those inaccuracies are part of the uncertainty produced by the lack of useful information about the cost of the HLW storage, and also by the ILW generated by reprocessing and not considered in the model.

This model has been applied to the results of some fuel cycle scenarios, where the number of packages to be stored was already published. Although the model has been developed for static cases, it can be used for dynamic cases, where the number of packages is a result of the simulation. Together with the GC unit cost developed here, this model allows estimating the final disposal cost for any fuel cycle (without specifying the repository design) with a small bias for open cycles and relatively small (considering the uncertainties) for scenarios with reprocessing. 
Table 6. FD cost for once-through nuclear fuel cycle scenarios.

\begin{tabular}{lcccl}
\hline Country & Mass $(\mathrm{tU})$ & Reference cost $(\mathrm{M} €)$ & TR_EVOL cost $(\mathrm{M} €)$ & Relative difference \\
\hline Finland & 5500 & 3330 & 3239 & $2.7 \%$ \\
Spain & 6765 & 3450 & 3475 & $1.1 \%$ \\
Sweden & 9471 & 3575 & 3814 & $6.6 \%$ \\
Canada & 192,000 & 14,167 & 13,826 & $2.4 \%$ \\
\hline
\end{tabular}

Table 7. FD cost for scenarios with partial reprocessing.

\begin{tabular}{lrcrccc}
\hline Country & $\mathrm{UO}_{2}$ SF & MOX SF & HLW & Ref. cost $(\mathrm{M} €)$ & TR_EVOL cost $(\mathrm{M} €)$ & Relative difference $(\%)$ \\
\hline Switzerland & 2200 & 0 & 52 & 3020 & 2780 & 7.9 \\
France & 17,600 & 4800 & 1320 & 13,981 & 12,409 & 11.2 \\
\hline
\end{tabular}

\section{Conclusions}

This work has satisfactorily demonstrated that the new capabilities of the fuel cycle scenario code TR_EVOL are accurate and reliable enough by means of comparing its results with those published in bibliography.

On the first hand, although the previous version of TR_EVOL had already been validated by means of benchmarking in the field of the OECD/NEA, the continuous updates and upgrades implemented to improve the fuel cycle model and the new economic module development required a new verification. This verification has been done cross checking the results of the code with the experimental data published for the Spanish nuclear fuel cycle scenario. In particular, the mass of spent fuel in reactor pools at year 2005 shows a relative deviation of around $2 \%$ between both TR_EVOL and ENRESA values, meaning that the model represents correctly the Spanish nuclear fleet, when making use of the new feature allowing variable burn-up, like for Cofrentes power plant.

On the second hand, three of the costs involved in the calculation of the LCOE (investment cost, fuel cost and O\&M cost) were cross checked against the results provided by the ARCAS European project. The generation costs of two fuel cycle scenarios with MA transmutation were evaluated: one involving an SFR and other involving an ADS. The results were highly satisfactory in both cases (less than $3 \%$ of difference regarding NRG calculations).

On the other hand, a specific economic analysis was carried out to calculate the back-end costs, specifically including the interim and final disposal costs. The first step consisted on using published data to fix the model parameters to use when the user does not have enough information about these cost types. Besides, a special methodology has been developed to take into account that in the final disposal a certain number of different waste forms can be stored depending on the characteristics of the fuel cycle scenario: spent fuel of different fuel types, vitrified high level waste, etc. This special methodology involved the concept of gallery length. With this model, the verification of the final disposal cost was achieved, finding a $7 \%$ difference in the comparison with the final disposal in a once-through scenario and around $11 \%$ in a final disposal with a

reprocessing strategy. These outcomes are highly acceptable given the difficulties to find in bibliography detailed information about the costs of the final disposals and the significant uncertainties involved in design concepts and related unit costs. A major outcome of this work is the possibility of estimating the final disposal cost for any fuel cycle scenario (without specifying the repository design) with a relatively small bias.

This work has been partially supported by ENRESA in the frame of the CIEMAT-ENRESA collaboration on Transmutation applied to High Level Waste and is part of the Ph.D. of I. Merino.

\section{Nomenclature}

ADS

BWR

DDD

$€$

EFIT

EP

FD

FC

FR

GC

GL

HLW

HM

IAEA

LCOE

$\mathrm{MA}$

MOX

NOC

OECD/NEA

O\&M

PRIS

PWR

SF

SFR

$\mathrm{UC}-\mathrm{V}$

$\mathrm{VC}$
Accelerator-Driven Subcritical System

boiling water reactor

Decommissioning, Dismantling and Disposal

Euros at 2012 price level

European Facility for Industrial-Scale Transmutation

encapsulation plant

final disposal

fixed cost

fast spectrum reactor

gallery cost

gallery length

high level waste

heavy metal

International Atomic Energy Agency

levelised cost of electricity

minor actinides

mixed uranium-plutonium oxide

number of canisters

Organisation for Economic Co-operation and Development/Nuclear Energy Agency

operation and maintenance

power reactor information system

pressurized light water reactor

spent fuel

sodium-cooled fast reactor

Universal Canisters - Vitrified

variable cost 


\section{References}

1. L. Boucher et al., Benchmark Study on Nuclear Fuel Cycle Transition Scenarios Analysis Codes, OECD/NEA NEA/ NSC/WPFC/DOC(2012)16, June, 2012

2. Nuclear Fuel Cycle Simulation System (VISTA), IAEATECDOC-1535, IAEA, 2007

3. Nuclear Energy in a Sustainable Development Perspective, OECD/NEA, ISBN: 926418278X, 2000

4. W.D. D'Haesseleer, Synthesis on the Economics of the Nuclear Energy, Study for the European Commission, Contract No. ENER/2012/NUCL/SI2.643067, 2013

5. F. Álvarez-Velarde, E.M. González-Romero, TR_EVOL, upgrading of EVOLCODE2 for transition scenario studies, in Proc. of the First Workshop on Technology and Components of the ADS (TCADS-1), OECD/NEA, Karlsruhe, Germany (2010)

6. A.G. Croff, A User's Manual for the ORIGEN2 Computer Code, ORNL/TM-7175, 1980

7. A.G. Croff, ORIGEN: a versatile computer code for calculating the nuclide compositions and characteristics of nuclear materials, Nucl. Technol. 62, 335 (1983)

8. F. Álvarez-Velarde, E.M. González-Romero, I. Merino Rodríguez, Validation of the burn-up code EVOLCODE 2.0 with PWR experimental data and with a Sensitivity/ Uncertainty analysis, Ann. Nucl. Energy 73, 175 (2014)

9. Cost Estimating Guideline for Generation IV Nuclear Energy Systems, The Economic Modeling Working Group of the Generation IV International Forum, GIF/EMWG/2007/ 004, 2007

10. About PRIS: http://www.iaea.org/pris/home.aspx

11. Sexto Plan General de Residuos Radiactivos, ENRESA Report 701-06-031-6, 2006

12. J.C. Manchobas et al., Nuclear España. Combustible, J. Spanish Nucl. Soc. 228 (2003)

13. ARCAS Project web page: http://cordis.europa.eu/proj ects $/ 249704$
14. F. Klaasen, A. Bidaud, A. van Heek, G. Van den Eynde, B. Lewin, C. Zimmerman, J. Uhlir, X. van Mierloo, A. Abánades, Economic comparison of Fast Reactors and Accelerator Driven system as dedicated burners, Deliverable 5, ARCAS EU 7th FP, Contract Number 249704, 2012

15. C. Artioli, H. Aït Abderrahim, G. Glinatsis, L. Mansani, C. Petrovich, M. Sarotto, M. Shikorr, Optimization of the minor actinide transmutation in the ADS: the European Facility for Industrial Transmutation EFIT-Pb concept, in Proc. of AccApp'07, Pocatello, Idaho, USA (2007)

16. L. De Pabitra, Cost of Decommissioning Nuclear Power Plants. A report on recent international estimates, IAEA Bulleting 3/1990, 1990

17. S. Bjurstrom, Status of the Swedish Nuclear Waste Management Program, in Proc. of the Symposium on Waste Management, Tucson, Arizona, USA (1988), Vol. II, p. 11

18. S. Petterson, H. Forsström, Costs for the Swedish radioactive waste management, in Proc. of the Symposium on Waste Management, Tucson, Arizona, USA (1992), Vol. I, p. 765

19. S. Kärnbränslehantering, Plan 2003: Costs for management of the radioactive waste products from nuclear power production, SKB 2003, Technical Report TR-03-11, 2003

20. Contribución a la selección y evaluación del comportamiento del material de relleno interno del contenedor de residuos de alta actividad, Final Report, Phase 1, ENRESA, 2006

21. Final disposal of spent nuclear fuel in Olkiluoto, POSIVA, Eura Print Oy 11/2011 2000, 2011

22. Cost Estimate for a Deep Geologic Repository for Used Nuclear Fuel, Radioactive Material Management, 1106/ MD18085/REP/02, 2003

23. M. Schneider, Y. Marignac, Spent nuclear fuel reprocessing in France, Research report of the International Panel on Fissile Materials, IPFM, 2008

24. D.E. Shropshire, K.A. Williams, J.D. Smith, B.W. Dixon, M. Dunzik-Gougar, R.D. Adams, D. Gombert, J.T. Carter, E. Schneider, D. Hebditch, Advanced Fuel Cycle Cost Basic, INL/EXT-07-12107, 2009

Cite this article as: Iván Merino-Rodríguez, Manuel García-Martínez, Francisco Álvarez-Velarde, Daniel López, Cross check of the new economic and mass balance features of the fuel cycle scenario code TR_EVOL, EPJ Nuclear Sci. Technol. 2, 33 (2016) 